\title{
Lacaziosis: Micosis cutánea profunda, reporte de un caso
}

Silvia Riggioni Víquez, Médico Residente del Posgrado de Dermatología, Universidad de Costa Rica. Teléfono: 88659208. Correo electrónico: s.riggioni@gmail.com

Silvia Díaz Araya, Médico Especialista en Dermatología, Servicio de Dermatología y Alergología., Hospital San Juan de Dios

Lugar de realización del trabajo: Servicio de Dermatología y Alergología, Hospital San Juan de Dios, Caja Costarricense de Seguro Social

\section{RESUMEN}

La lacaziosis es una rara micosis cutánea y subcutánea, de evolución crónica, ocasionada por el hongo profundo Lacazia loboi. Ha sido descrita principalmente en regiones tropicales y subtropicales. Clínicamente se caracteriza por lesiones cutáneas de aspecto queloideano y progresión lenta. La enfermedad se presenta más frecuentemente en adultos varones que desempeñan actividades laborales en el campo. Se presenta el caso de un paciente masculino de 68 años, agricultor, con una dermatosis crónica localizada en el miembro superior derecho, caracterizada por una neoformación compuesta por múltiples lesiones nodulares de aspecto queloideano con una lesión satélite proximal. El diagnóstico histopatológico fue compatible con una lacaziosis.

\section{PALABRAS CLAVE}

Lacaziosis, lobomicosis, Lacazia loboi, micosis cutánea profunda, zoonosis.

\footnotetext{
ABSTRACT

Lacaziosis is a rare cutaneous and subcutaneous mycosis, caused by the fungus Lacazia loboi. It has been mainly described in the tropical and subtropical regions. The disease has a slow and chronic clinical progression, characterized by keloid-like cutaneous lesions. Most cases have been described in adult males who work in the countryside. We present the case of a 68 year old male, farmer, with a chronic dermatosis localyzed in his upper right arm, composed of multiple nodular lesions of keloidian aspect with a proximal satellite lesion. The hystopathological diagnosis revealed a deep fungal mycosis compatible with lacaziosis.
}

\section{KEY WORDS}

Lacaziosis, lobomycosis, Lacazia loboi, deep tissue mycosis, zoonosis.

\section{PRESENTACIÓN DE CASO}

Masculino de 68 años, agricultor, vecino de la zona de San Vito de Coto Brus, con antecedentes personales patológicos de hipertensión arterial y cardiopatía hipertensiva, en control en el Hospital Escalante Pradilla.

Consulta referido de su hospital regional, al Servicio de Dermatología y Alergología del Hospital San Juan de Dios, con historia de dermatosis de 8 años de evolución, localizada a nivel del miembro superior derecho. Niega sintomatología asociada a la lesión. Al examen físico se documenta una neoformación compuesta por múltiples lesiones nodulares confluentes, de aspecto queloideano, sobre una piel de características no inflamatorias. En sentido proximal de la extremidad, se documenta otra lesión satélite, única, de características similares. No se evidenciaron adenopatías axilares izquierdas palpables. (Figura 1)

Se decide corroborar la presunción diagnóstica de una micosis profunda mediante la toma de una biopsia incisional, la cual se envía a analizar al Laboratorio de Patología del Hospital San Juan de Dios. La histopatología documentó piel que mostraba a nivel de la dermis papilar y reticular un extenso infiltrado inflamatorio crónico granulomatoso (Figura 2) y se identificaron múltiples estructuras fúngicas redondeadas de pared gruesa, algunas formando cadenas, dentro de células gigantes multinucleadas. (Figura 3) 
El diagnóstico realizado fue de Lacaziosis. El paciente fue consecuentemente sometido a escisión quirúrgica parcial de la lesión en un primer tiempo, con adecuada evolución y continúa en control para futuras escisiones quirúrgicas.

\section{DISCUSIÓN}

La lacaziosis fue descrita inicialmente en 1930 por Jorge Lobo, en un paciente de 52 años proveniente de Recife, ciudad al noreste de Brazil, que presentaba lesiones nodulares en la región lumbosacra y glútea. El examen directo y la histología demostraron la presencia de un organismo similar al Paracoccidiodes brasiliensis. ${ }^{1}$ Inicialmente se describió como una variante de la paracoccidiodomicosis, siendo posteriormente reclasificado como una entidad etiológicamente distinta. El primer caso descrito en América Central se dio en $1950 .^{2}$

A través del tiempo, esta enfermedad ha recibido varios nombres: Blastomicosis queloideana, Enfermedad de Jorge Lobo, Blastomicosis tipo Jorge Lobo, Falsa lepra, Blastomicosis amazónica pseudoleprosa, Lepra de los Caiabi, Lobomicosis y recientemente, Lacaziosis. ${ }^{1,2}$

La lacaziosis humana se ha descrito principalmente en nueve países suramericanos y tres centroamericanos, entre los cuales se encuentra Costa Rica. ${ }^{3}$ Reportes incidentales en zonas fuera del área tropical $\mathrm{y}$ subtropical son escasos.

La clasificación taxonómica del agente etiológico de esta patología ha sido controvertida y cambiante a lo largo de los años, debido principalmente a su incapacidad de ser cultivado. Desde su primera denominación como Glenosporella loboi en 1940 (Fonseca-Leão), ha recibido variadas nominaciones: Glenosporopsis amazónica (Fonseca, 1943), Blastomyces loboi (Vanbreuseghem, 1952), Paracoccidiodes loboi (Almeida-Lacaz, 1948), Loboa loboi (F.C.Odds, 1992) y Lacazia loboi (Taborda, 1999). ${ }^{3}$

El nombre recomendado actualmente para su agente etiológico corresponde a Lacazia loboi, razón por la cual se prefiere llamar a esta micosis profunda Lacaziosis, en lugar de su designación más conocida, Lobomicosis.

L. loboi es un hongo que desarrolla su estado saprófito en la vegetación, tierra y agua. Las áreas comúnmente afectadas se caracterizan por ser de densa vegetación, localizadas a 200-250 metros sobre el nivel del mar, con precipitaciones de lluvia anuales de $2000 \mathrm{~mm}^{3}$, temperaturas promedio de $24{ }^{\circ} \mathrm{C}$ y humedad relativa del $75 \%$. ${ }^{4}$ Por lo tanto, la mayoría de los casos son provenientes de la región del Amazonas y América Central.

No se describe predilección de acuerdo a la etnia, pero sí existe predominancia por el sexo masculino, posiblemente por exposición laboral. La edad promedio de los pacientes afectados varía entre los 40-70 años, existen pocos casos en niños. Se consideran actividades de alto riesgo para adquirir esta patología la minería, agricultura, pesca y caza. ${ }^{4}$

Su mecanismo de ingreso e infección a los humanos es a través de traumas cutáneos. Se ha descrito incluso inoculación por picaduras de serpientes e insectos. No se describe transmisión de humano a humano.

Una vez en la dermis, es fagocitado por células del sistema mononuclear, dentro de las cuales lleva a cabo un lento proceso de incubación, replicación y desarrollo de las lesiones. Se ha descrito una posible deficiencia antígeno específica en el sistema inmune celular de los pacientes afectados, en la cual la actividad del sistema fagocitario puede verse afectada por el factor de crecimiento transformador $\beta$, una citosina que suprime la actividad macrofágica e inhibe la expresión del óxido nítrico e interferón gamma. Así mismo, se ha propuesto que las células de Langerhans juegan un papel en la modulación del sistema inmune, ocasionando evasión en la presentación del antígeno fúngico. $2,4,5$

Clínicamente, la enfermedad se caracteriza por lesiones pleomórficas. La presentación más común es la nodular, con una lesión sólida, localizada, de superficie lisa y brillante, semejante al aspecto de una cicatriz queloide. Otras variantes descritas son: infiltrativa, gomatosa, ulcerativa, verrucosa, tumoral, esclerodermiforme, macular y en placa. ${ }^{1,5}$ La lesión puede ser asintomática, dolorosa a la palpación, pruriginosa, hipoestésica o anestésica.

Topográficamente, las lesiones suelen encontrarse en áreas expuestas. En orden de frecuencia se describen: extremidades inferiores $(32 \%)$, oído externo $(25 \%)$, extremidades superiores $(22 \%)$, cara $(7 \%)$, diseminado $(8 \%)$, sacro $(3 \%)$, tórax $(2 \%)$ y cuello $(1 \%) .^{5}$

Dentro de las complicaciones puede existir restricción de movimientos en lesiones yuxtaarticulares, compromiso estético, infección secundaria por 
piógenos y degeneración hacia carcinoma epidermoide.

El examen directo de las lesiones revela levaduras de pared gruesa, refringentes, de doble contorno, que miden aproximadamente $5 \times 14 \mu \mathrm{m}$. Se reproduce por gemación simple. Los patrones en rosario o cadena son frecuentes. Se evidencian mejor con tinciones de PAS y Groccot-Gomori. ${ }^{1}$

En la histopatología, la epidermis puede encontrarse atrófica, hiperplásica o ulcerada. Puede evidenciarse eliminación transepidérmica del hongo. La dermis muestra un infiltrado granulomatoso, nodular o difuso, compuesto por macrófagos y células gigantes multinucleadas tipo Langerhans y cuerpo extraño. Pueden haber histiocitos espumosos con gran cantidad de parásitos. Es infrecuente la presencia de un infiltrado inflamatorio compuesto por linfocitos y células plasmáticas entre las células fagocíticas y a nivel perivascular. ${ }^{1}$

El diagnóstico se basa en la siguiente tríada: 1) ausencia de crecimiento del hongo en el cultivo, 2) presencia de organismos similares a levaduras en el examen microscópico directo de la lesión, 3) histopatología característica de Lacaziosis. ${ }^{7}$ La histopatología es considerada el estándar de oro para el diagnóstico.

El tratamiento de elección es la escisión quirúrgica, principalmente en lesiones localizadas, recomendándose márgenes amplios pues la recurrencia es frecuente. En lesiones grandes y multifocales se ha utilizado la combinación de itraconazol más crioterapia con nitrógeno líquido. Se han descrito otras terapias con resultados poco satisfactorios. ${ }^{1,8}$

\section{CONFLICTO DE INTERÉS}

No hay conflicto de interés

\section{BIBLIOGRAFÍA}

1. Ramos-E-Silva M, Aguiar-Santos-Vilela F, Cardoso-de-Brito A, Coelho-Carneiro S. Lobomycosis: Literature review and future perspectives. Actas Dermosifiliogr. 2009 Nov;100 Suppl 1:92-100.

2. Paniz-Mondolfi A, Talhari C, Sander Hoffmann L, Connor DL, Talhari S, Bermudez-Villapol L, et al. Lobomycosis: an emerging disease in humans and delphinida e. Mycoses. 2012 Jul;55(4):298-309.

3. Paniz-Mondolfi AE, Reyes Jaimes O, Dávila Jones L. Lobomycosis in Venezuela. Int $\mathrm{J}$ Dermatol. 2007 Feb;46(2):180-5.

4. Talhari S, Talhari C. Lobomycosis. Clin Dermatol. 2012 Jul-Aug;30(4):420-4.

5. Garzón-Aldaz, Herrera-Vicuña. Lobomicosis: una serie de 5 casos. Piel. 2013; 28(5):260263.

6. Papadavid E, Dalamaga M, Kapniari I, Pantelidaki E, Papageorgiou S, Pappa V, et al. Lobomycosis: A case from Southeastern Europe and review of the literature. J Dermatol Case Rep. 2012 Sep 28;6(3):65-9.

7. Nogueira L, Mendes L, Rodrigues CA, Santos M, Talhari S, Talhari C. Lobomycosis and squamous cell carcinoma. An Bras Dermatol. 2013 Mar-Apr;88(2):2935.

8. Carneiro FP, Maia LB, Moraes MA, de Magalhães AV, Vianna LM, Zancanaro PC, et al.

Lobomycosis: diagnosis and management of $r$ elapsed and multifocal lesions. Diagn Microbiol Infect Dis. 2009 Sep;65(1):62-4. 
Figura 1: Iconografía de la lesión presentada por el paciente en la extremidad superior derecha

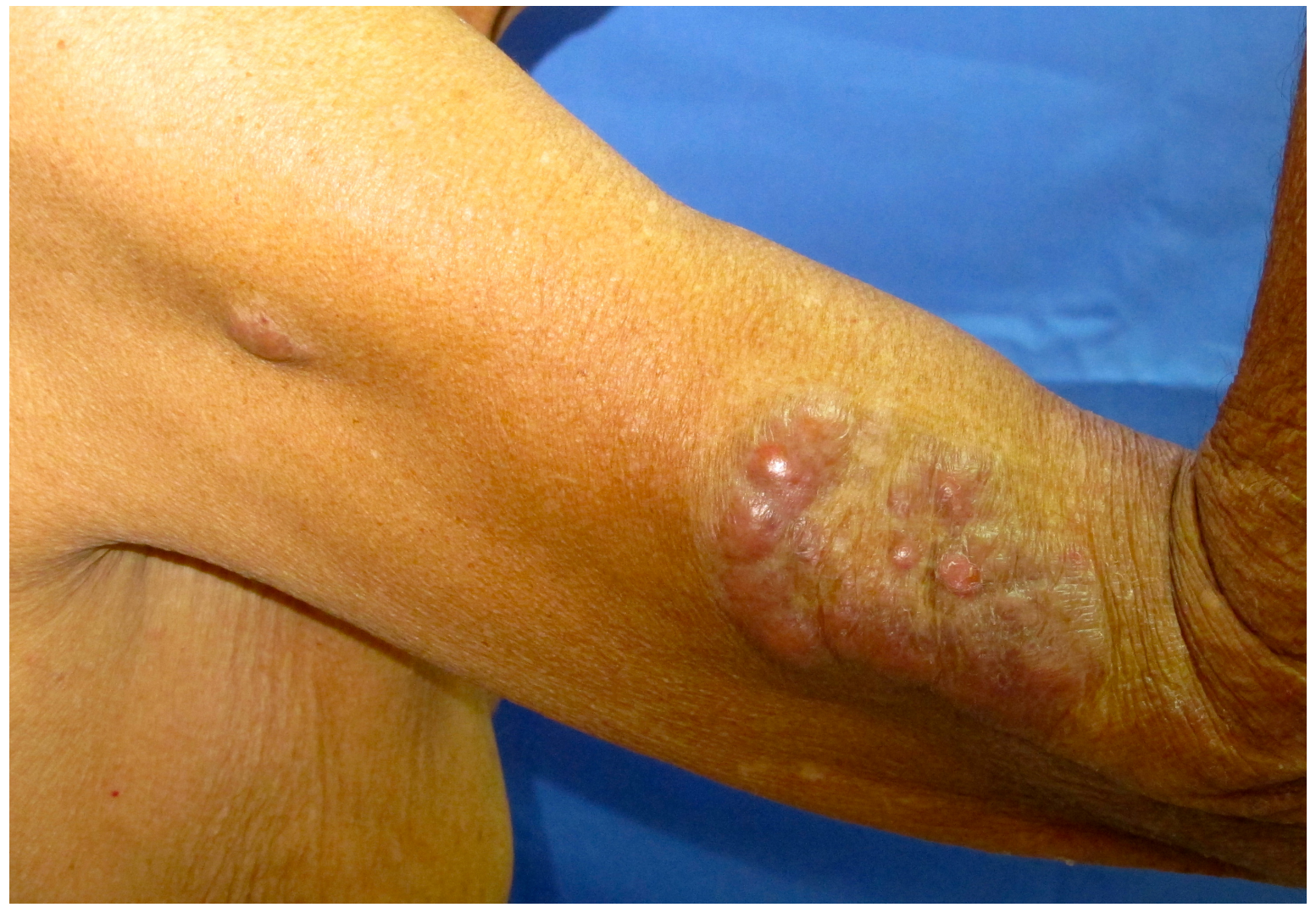


Figura 2: Histopatología a bajo poder de la lesión, mostrando la dermis papilar y reticular con un extenso infiltrado inflamatorio crónico granulomatoso

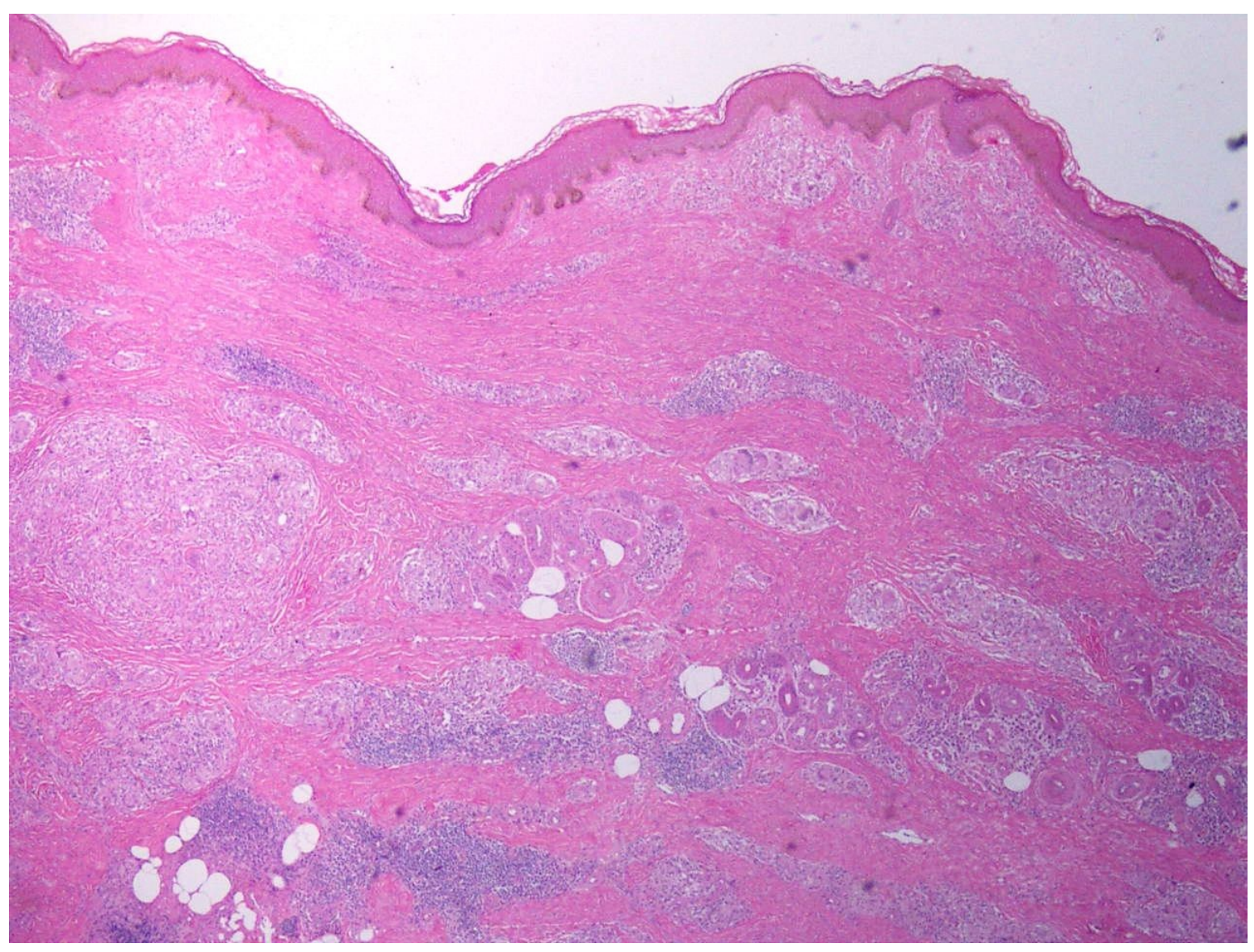


Figura 3: Histopatología a mayor aumento, evidenciando estructuras fúngicas redondeadas características de la Lacaziosis

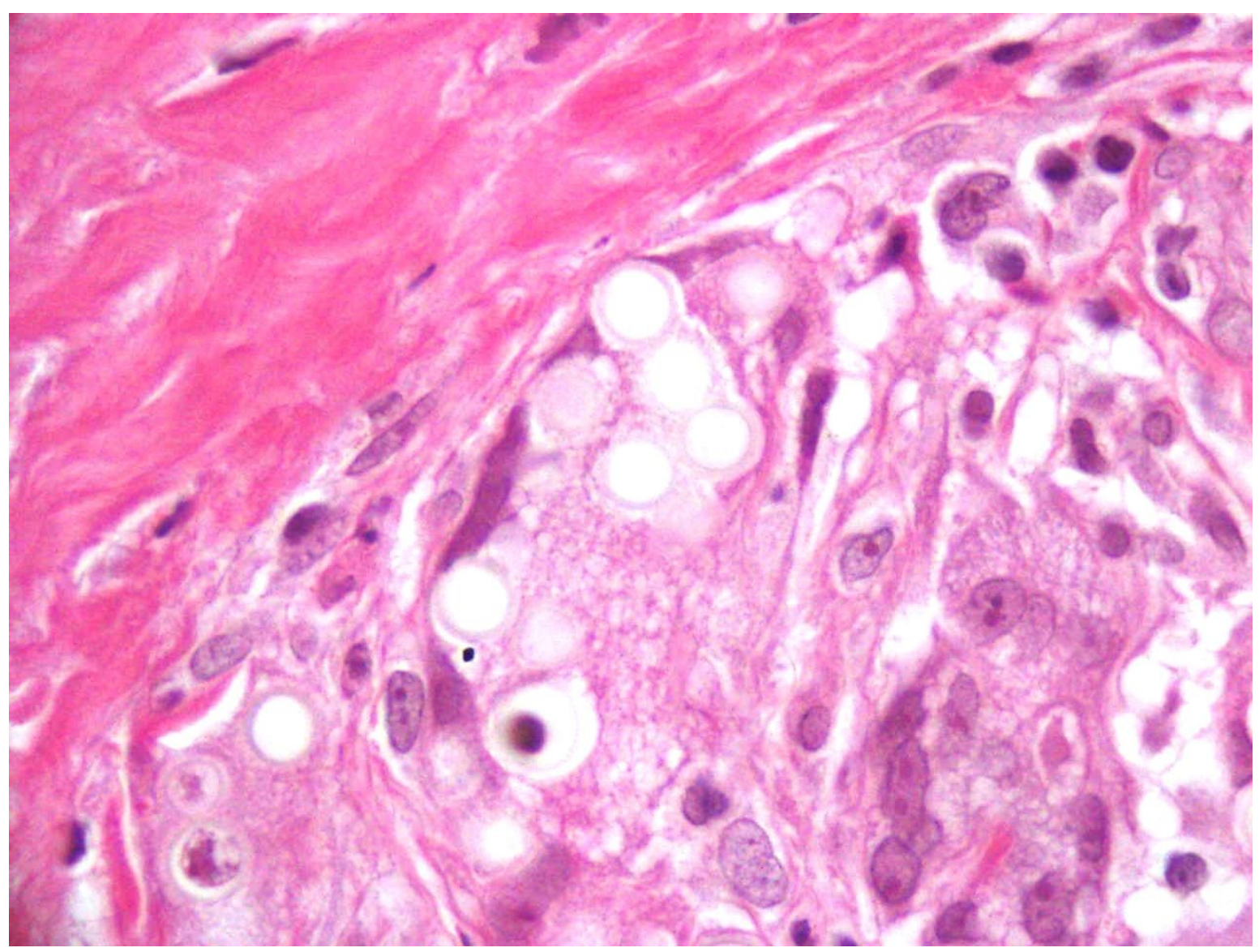

